\title{
Synthesis of AgNPs Embedded Double Network Nanocomposite Hydrogels having High Swelling and Anti-Bacterial Characteristics
}

\author{
Akansha Dixit ${ }^{1}$, Nand Kumar ${ }^{1}$, Dibyendu S. Bag ${ }^{1 *}$, Kavita Agarwal ${ }^{1}$, Dhirendra K. Sharma ${ }^{2}$, \\ N. Eswara Prasad ${ }^{1}$
}

\author{
${ }^{1}$ Defence Materials and Stores Research and Development Establishment, DMSRDE, P.O., G.T. Road, \\ Kanpur 208013, India \\ ${ }^{2}$ Department of Chemistry, Bundelkhand University, Jhansi 284128, India
}

*Corresponding author: E-mail: ds_bag@ @rediffmail.com

Received: 22 August 2018, Revised: 09 December 2018 and Accepted: 13 December 2018

DOI: $10.5185 /$ amlett.2019.2258

www.vbripress.com/aml

\begin{abstract}
Silver nanoparticles (AgNPs) embedded double network (DN) nanocomposite hydrogels [of P(AM-co-HEMA) as second network and PVA-Borax as first network] were synthesized by in-situ reduction of silver nitrate using citric acid in presence of the fully swollen high strength DN hydrogels. The AgNPs embedded DN nanocomposites hydrogels (Ag-DNG) were characterized by FTIR, XRD and TEM analyses. Such Ag-DNG hydrogels were studied for their degree of swelling and swelling kinetics. They were also evaluated for their anti-bacterial characteristics using a Gram negative (Escherichia coli) and a Gram positive (Bacillus subtilis) bacteria. The XRD analysis revealed the presence of AgNPs in the DN nanocomposite hydrogels. The AgNPs were observed to be $20-50 \mathrm{~nm}$ in diameter as observed by TEM analysis. The degree of swelling of Ag-DNG hydrogels was lower than that of the virgin DN hydrogel which was because of the space of pores of the DN hydrogels occupied by AgNPs. The virgin DN hydrogels did not exhibit any antimicrobial property, whereas Ag-DNG hydrogels exhibited a significant amount of antibacterial activity towards gram positive and gram negative bacteria. Such AgNPs incorporated high strength DN nanocomposite hydrogels may find potential biomedical application. Copyright $\odot$ VBRI Press.
\end{abstract}

Keywords: Nanocomposite hydrogels, double network (DN) hydrogels, silver nanoparticles, antibacterial properties.

\section{Introduction}

Hydrogels are swollen crosslinked polymeric networks in aqueous medium. Smart/intelligent hydrogels have virtue to respond to the external stimuli like temperature, pressure, electric \& magnetic field, ionic strength and $\mathrm{pH}$ of the media, etc. [1-4]. They are soft and rubbery materials having usually excellent biocompatibility. They have high permeability for water soluble metabolites, oxygen and nutrients which make them attractive scaffolds in the tissue engineering [5]. These materials are used in a variety of applications including ophthalmology, drug delivery, orthopedics and many other medical devices [6-8]. In the recent years, hydrogels have been utilized for bone-tissue engineering application because they could provide the gelling medium in which the phenomenon of biomineralization takes place [9-13]. Generally, hydrogels are soft but brittle especially in their swollen state. So, such soft hydrogel materials have been strengthened by various approaches which include: Double Network (DN) hydrogels [14-18], Topological (TP) hydrogels $[\mathbf{1 9}, \mathbf{2 0}]$, Hybrid hydrogels $[\mathbf{2 1}, 22]$ and
Nanocomposite (NC) hydrogels [23-28].The double network hydrogels consist of one type of polymerized monomer which was crosslinked in presence of another crosslinked network. They have high molecular mass [14-18]. A hydrogel consisting of tightly crosslinked first network poly (2-acrylamid-2 methylpropanesulfonic acid) (PAMPS) and uncrosslinked second network of polyacrylamide (PAM) is a kind interpenetrating gel which is very tough in nature. The DN hydrogels having 90 wt. \% water content exhibited high compressive strength, strain as well as toughness $[\mathbf{1 4}, \mathbf{2 9}]$. Beside this, hydrogels based on methylacrylates are non-toxic, biocompatible, non-immiuno-reactive and have controllable porosity [30]. Methacrylate hydrogels have also been employed in drug delivery systems, contact lenses, tissue regeneration, bio-sensoring and tissue expanders in dentistry [31-37].

Synthesis of hydrogels with antibacterial properties has been a special interest because of their biomedical applications as these soft materials have the features similar to biological tissues. Bactericidal agents mixed hydrogels have been prepared and reported by many 
researchers [38-39]. Addition of metal nanoparticles into hydrogels is a promising approach to synthesize antibacterial hydrogels [40-41]. Silver nanoparticles possess anti-inflammatory and anti-angiogenic activity and are also effective in fighting against bacteria, viruses and eukaryotic microorganisms [42-45]. Silver particles have also been applied in wide area of health care products like burn dressings, scaffold, water purification systems, skin donor and recipient sites, and medical devices [46-50]. Many synthetic routes for the preparation of silver nanoparticles have also been developed and reported in literature [51-53]. We have also earlier reported the fullerene incorporated polyHEMA and polyNIPAM based thermo-responsive nanocomposite hydrogels [54-55].

In this investigation, we have synthesized AgNPs embedded double network nanocomposite hydrogels by in-situ reduction process of silver nitrate using citric acid as reducing agent in the swollen high strength DN hydrogels. DN hydrogels used in this investigation were consisting of PVA-borax as $1^{\text {st }}$ network and crosslinked acrylamide (AM) or 2-hydroxyethyl methacrylate (HEMA) or AM/HEMA copolymer as $2^{\text {nd }}$ network [56]. Poly(vinyl alcohol) (PVA) is a non-toxic, water soluble polymer and is very popular as a hydrogel material for biomedical applications. Borax is a salt of boric acid and is also used as antifungal agent. AM and HEMA are well-known functional monomers widely studied for their hydrogel properties. Thus the DN hydrogels described here obtained from the judicial selection of the above chemicals having sufficient mechanical properties are very unique in nature and they may have possible biomedical application. The investigation of embedding AgNPs into such DN hydrogels and the study of their antibacterial properties are very crucial. The antibacterial properties of such hydrogels were tested using a gram positive (B. subtilisis) and a gram negative (E. coli) bacteria. The degree of swelling, and swelling kinetics of such AgNPs embedded DN nanocomposite hydrogels have been studied and compared with the virgin DN hydrogels. They have also been characterized by the FTIR, XRD and TEM analyses.

\section{Experimental}

\section{Materials}

The monomers, acrylamide (AM) (97\%, Koch-light Laboratories, UK) and 2-hydroxyethyl methacrylate (HEMA) (97\%, Lancaster, England) were used as received. The crosslinker, N, N'-methylene-bisacrylamide (MBA) (LR, SigmaAldrich, USA) was recrystallized from ethanol and further dried under vacuum before use. The initiator, ammonium persulfate (APS) (AR, SD Fine Chem. Pvt. Ltd., India) and accelerator, $\mathrm{N}, \mathrm{N}, \mathrm{N}^{\prime}, \mathrm{N}^{\prime}$-tetramethylethylenediamine (TMEDA) (98\%, Lancaster, UK) were used as received. Silver nitrate (98\%) and citric acid (98\%) were obtained from Sigma Aldrich (USA) and also used as received. Di-sodium tetra borate (Borax) (98\%,
Qualigens, India) and poly (vinyl alcohol) (88\% hydrolyzed \& $\overline{M_{w}}=22000 \mathrm{gmol}^{-1}$ ) (Across Organics, USA) were employed directly as received.

\section{Synthesis of double network (DN) hydrogels}

Double network hydrogels (coded as DNG-1, DNG-2 and DNG-3) were synthesized through insitu crosslinking polymerization of AM and HEMA using MBA as crosslinker and APS as initiator along with TMEDA as accelerator in the presence of PVA-borax network system as reported by our group previously [56].The compositions of such DN hydrogels are provided in Table 1.The structure of the two networks in DN hydrogels is given in Fig. 1. All the synthesized hydrogel samples were dried at $60^{\circ} \mathrm{C}$ for $24 \mathrm{hrs}$ and they were weighed till constant weight.

Table 1. Synthesis of DN hydrogels ${ }^{\mathrm{a}, \mathrm{b}}$.

\begin{tabular}{c|c|c}
\hline SI.No. & Sample Code & Amount of AM/HEMA (wt/wt \%) \\
\hline 1. & DNG-1 & $100 / 0$ \\
\hline 2. & DNG-2 & $50 / 50$ \\
\hline 3. & DNG-3 & $0 / 100$ \\
\hline
\end{tabular}

a. First network: $25 \mathrm{ml}$ of $4 \mathrm{wt} \%$ aqueous solution of PVA and $5 \mathrm{ml}$ of $4 \mathrm{wt}$. \% of borax solution.

b. Second network: monomer (AM or HEMA or AM/HEMA) mixture $10 \mathrm{~g}$, initiator concentration 1 wt \% of total monomer, crosslinker (MBA) conc.: 0.1 wt \% of total monomer. Polymerization was carried out at room temperature $\left(25^{\circ} \mathrm{C}\right)$ for $24 \mathrm{hrs}$
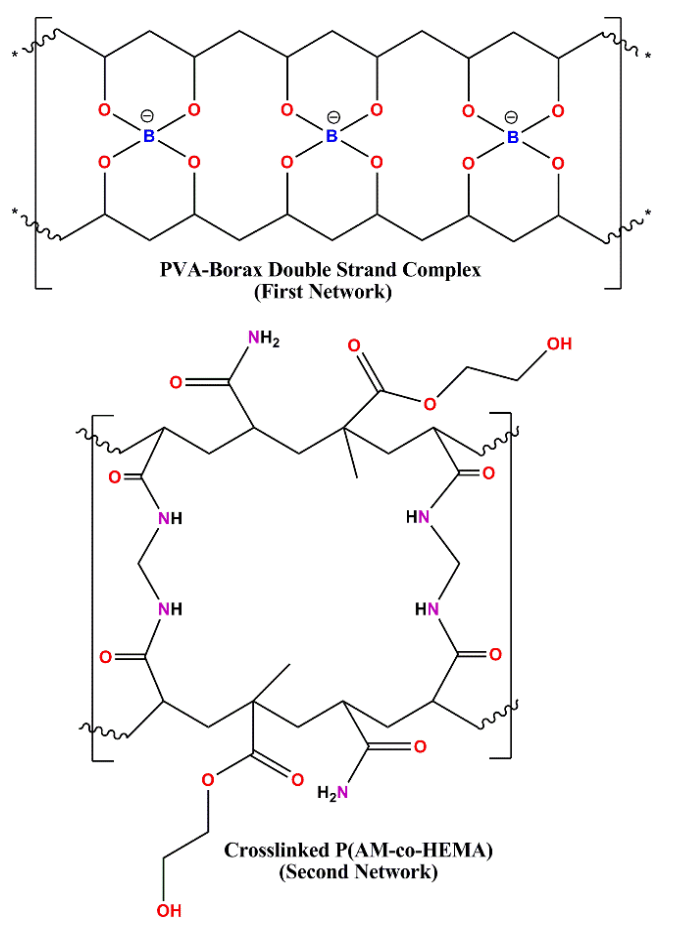

Fig. 1. Chemical Structures of two Networks of Double Network Hydrogels (DNG).

\section{Synthesis of silver nanoparticle embedded DN nanocomposite hydrogels}

A synthesized dry DN hydrogel sample was put in distilled water for $48 \mathrm{hrs}$ to allow equilibrium swelling. A solution of $\mathrm{AgNO}_{3}$ (amount: 10 wt \% of a dry hydrogel sample) was prepared in $200 \mathrm{ml}$ distilled 
water. The fully swollen hydrogel sample was then taken out and immersed in the $\mathrm{AgNO}_{3}$ solution for 24 hrs. to make the complete dispersion/impregnation of $\mathrm{Ag}+$ ions in the swollen hydrogel. The Ag+ ions trapped hydrogel sample was then taken out and further immersed in $200 \mathrm{ml}$ of aqueous citric acid solution (10 wt \% of dry hydrogel sample) for next $24 \mathrm{hrs}$ in order to reduce the $\mathrm{Ag}+$ ions into $\mathrm{Ag}$-nanoparticles. Reduction of $\mathrm{Ag}+$ to $\mathrm{Ag}$ in the hydrogel sample was observed by the color change from transparent to dark brown. The synthesis is shown in Scheme 1. Similar procedure was adapted for all the hydrogels samples for impregnation of AgNPs into them. The silver nanoparticle embedded DN nanocomposite hydrogels (Ag-DNG) were dried in oven at $60^{\circ} \mathrm{C}$ for $48 \mathrm{hrs}$ and then they were weighed again. The wt $\%$ of AgNPs entrapped in the DN nanocomposite hydrogels were obtained as $6.91 \mathrm{wt} \%, 4.86 \mathrm{wt} \%$ and $2.67 \mathrm{wt} \%$ for Ag-DNG-1, Ag-DNG-2and Ag-DNG-3, respectively.

\section{Characterization}

\section{Swelling study}

The swelling study of the synthesized AgNPs embedded nanocomposite hydrogels was carried out through gravimetric method [56]. The Ag-DNG hydrogels were first dried in a vacuum oven and then weighed. The dried samples were dipped in distilled water and allowed to swell at room temperature. The swollen Ag-DNG samples were taken out and the excess water on their surface was wiped up using filter paper, and then they were weighed again. This procedure was repeated at regular time intervals untill the weight of the swollen samples became constant after achieving equilibrium swelling. The degree of swelling was measured using the following equation:

Degree of swelling (or extent of swelling or water uptake):

$$
\left(\mathrm{S}_{\mathrm{w}}\right)=\left(\mathrm{W}_{\mathrm{t}}-\mathrm{W}_{0}\right) / \mathrm{W}_{0}
$$

where, $\mathrm{W}_{\mathrm{t}}=$ weight of a swollen hydrogel after a particular swelling time $(\mathrm{t})$ and $\mathrm{W}_{0}=$ weight of the dry hydrogel sample (taken for swelling study).

\section{Swelling kinetics}

The 'swelling kinetics' of the synthesized AgNPs embedded double network nanocomposite hydrogels was determined to elucidate the controlling mechanism of the swelling processes. A kinetic analysis represented by a second-order equation was employed in this investigation using the following relationship [57-59]:

$$
\frac{d S}{d t}=\mathrm{K}_{\mathrm{s}}\left(\mathrm{S}_{\mathrm{eq}}-\mathrm{S}\right)^{2}
$$

where, $\mathrm{dS} / \mathrm{dt}=$ rate of swelling, $\mathrm{K}_{\mathrm{s}}=$ swelling rate constant and $S_{\mathrm{eq}}=$ degree of equilibrium swelling.

The above equation 2 was integrated and after applying the condition $\mathrm{S}=0$ at $\mathrm{t}=0$ and $\mathrm{S}=\mathrm{S}_{\mathrm{w}}$ at $\mathrm{t}=\mathrm{t}$, we obtained the following equation:

$$
\frac{t}{s}=A+B t
$$

where, $\mathrm{B}=1 / \mathrm{S}_{\mathrm{eq}}$ which is inverse of equilibrium swelling and $A=1 / K_{s}\left(S_{e q}{ }^{2}\right)$ which is the inverse of rate of swelling at initial state i.e., $\left[(\mathrm{dS} / \mathrm{dt})_{0}\right]$. So, we can write $S_{\mathrm{eq}}=1 / \mathrm{B}$ and $\mathrm{K}_{\mathrm{s}}=\left(\mathrm{B}^{2} / \mathrm{A}\right)$.

Besides the above kinetic scheme of hydrogel swelling, the mechanism of diffusion of water into the Ag-DNG hydrogels was evaluated using the following kinetic equation [60]:

Or

$$
S_{w}=\frac{W_{t}-W_{0}}{W_{0}}=\mathrm{kt}^{\mathrm{n}}
$$

$$
\log S_{w}=\log \mathrm{k}+\mathrm{n} \log \mathrm{t}
$$

where, $\mathrm{k}=$ swelling characteristic constant and $\mathrm{n}=$ diffusion (transport) exponent. The values of ' $\mathrm{k}$ ' and ' $\mathrm{n}$ ' were evaluated by plotting $\log S_{w}$ versus $\operatorname{logt}$, where the value of ' $k$ ' was obtained from the intercept and ' $n$ ' from the slope.

\section{FTIR analysis}

The synthesized silver nanoparticles embedded double network nanocomposite hydrogels were characterized by FTIR analysis. FTIR spectra of the samples were recorded on a Perkin Elmer (Spectrum 100 Series) spectrophotometer using $\mathrm{KBr}$ pellets.

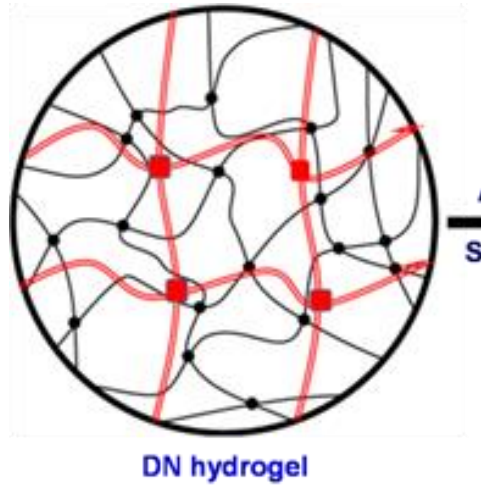

DN hydrogels:

-14t Network: PVA-borax

-2 ${ }^{\text {nd }}$ Network: Crosslinked AM/HEMA

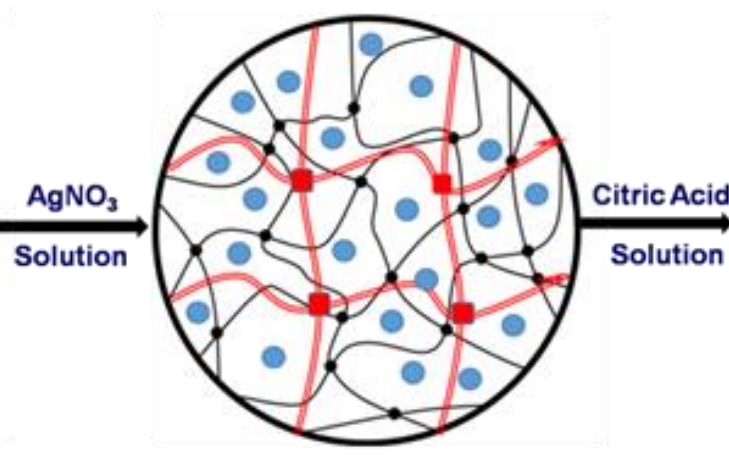

$\equiv \mathrm{Ag}+$ ion

- $\equiv$ Ag NPs

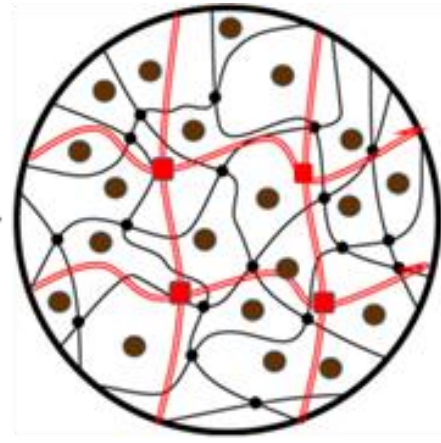

AgNPs Embeded Nanocomposite DN Hydrogel

Scheme 1. Synthesis of Silver Nanoparticles Embedded DN Nanocomposite Hydrogels. 


\section{$X$-ray diffraction $(X R D)$ analysis}

$\mathrm{X}$-ray diffraction patterns of the virgin as well as Agnanoparticles incorporated nanocomposite hydrogels were recorded on an XRD-6000 diffractometer with $\mathrm{CuK}_{\alpha}$ target $(40 \mathrm{kV}, 15 \mathrm{~mA})$, and with a scanning rate of $5^{\circ} \mathrm{min}^{-1}$.

\section{Transmission Electron Microscope (TEM) analysis}

TEM images for the virgin DN hydrogels and nanosilver embedded DN nanocomposite hydrogels were recorded using a FEI Tecnai G2 12 Twin Transmission Electron Microscope (TEM) operating at an acceleration voltage of $120 \mathrm{KV}$. Specimens for TEM analysis were prepared by the placement of sample solutions on 400-mesh copper grids followed by evaporation of excess water-ethanol in air under ambient condition $\left(25{ }^{\circ} \mathrm{C}\right)$. Particle sizes were determined from the TEM images.

\section{Antibacterial assay}

The prepared Ag-DNG nanocomposite hydrogel samples were taken in vitro for their antibacterial activities against Escherichia coli (Gram negative) and Bacillus subtilis (Gram positive) bacteria.

The agar diffusion method was utilized for this procedure [61]. Nutrient agar media were used to maintain the bacteria growth. The agar was taken in $50 \mathrm{~mL}$ quantity in different conical flasks and incubated with $0.5 \mathrm{~mL}$ test organism cell suspensions at $40-50{ }^{\circ} \mathrm{C}$. The conical flasks were shaken well and then the solutions were poured into petri dishes and allowed to solidify. When the solidification was completed, holes (with diameter $10 \mathrm{~mm}$ ) were made on the agar plates with the help of sterile cork pourer. The prepared Ag-DNG hydrogels were then cut into small pieces and allowed to swell in sterile distilled water and then put on agar surface. The petri dishes were maintained at $5{ }^{\circ} \mathrm{C}$ for about $1 \mathrm{hr}$ to allocate the diffusion of the Ag-DNG hydrogel samples through agar medium and to hinder the growth of the test organism. Petri dishes were incubated for $24 \mathrm{hrs}$ at $30^{\circ} \mathrm{C}$ for bacteria growth. The diameters (in $\mathrm{mm}$ ) of the consequent inhibition zones were then measured. It should be noted that higher the diameter of inhibition zone, higher will be the antimicrobial activity of the AgNPs embedded DN nanocomposite hydrogels [61].

\section{Results and discussion}

\section{FTIR analysis}

The silver nanoparticles embedded DN nanocomposite hydrogels were characterized by FTIR analysis. The FTIR spectra of a virgin DN hydrogel and silver nanoparticles embedded nanocomposite hydrogel are shown in Fig. 2. It can be observed from the spectra that a broad large peak appearing at $3230-3450 \mathrm{~cm}^{-1}$ is due to the consequence of stretching of the hydroxyl groups $(\mathrm{OH})$ present in the PVA and HEMA components of the DN hydrogels. The peak due to stretching of $\mathrm{N}-\mathrm{H}$ of amide group of AM unit is merged with the above band. Further, the peak appearing at $2850 \mathrm{~cm}^{-1}$ is attributed to the $\mathrm{C}-\mathrm{H}$ stretching of methyl $\left(-\mathrm{CH}_{3}\right)$ group and alkyl $\left(-\mathrm{CH}_{2}-\right)$ chains. The characteristic peak of PVA and borax crosslinked structure is observed at $1330 \mathrm{~cm}^{-}$ ${ }^{1}$ which is due to the stretching of $\mathrm{B}-\mathrm{O}-\mathrm{C}$ bond. It is the indication of formation of complex between the PVA and borate [62-64]. Besides this, the band appearing at $1735 \mathrm{~cm}^{-1}$ is due to the carbonyl $(\mathrm{C}=\mathrm{O})$ group of ester of HEMA unit. The carbonyl $(\mathrm{C}=\mathrm{O})$ stretching band of amide group of acrylamide unitis is appeared at $1655 \mathrm{~cm}^{-1}$. However, on comparing the spectrum of AgNPs impregnated nanocomposite hydrogel (Ag-DNG-2) with the virgin DN hydrogel (DNG-2), it is observed that the peak of hydroxyl $(-\mathrm{OH})$ stretching is shifted from $3421 \mathrm{~cm}^{-1}$ (in DNG-2) to $3450 \mathrm{~cm}^{-1}$ (in Ag-DNG-2). This shift of stretching vibration of hydroxyl group at higher frequency (in Ag-DNG-2 hydrogel) may be associated with the coordination of such group with the $\mathrm{Ag}+$ ion through ion-dipole interaction. The result of such interaction led to the shortening of $\mathrm{OH}$ bond which ultimately reflected in the increase in stretching frequency of hydroxyl group (Fig. 2). Similar $\mathrm{Ag}+$ ion-ligand interaction was also reported in AgNPs containing poly (acrylamide - co acrylic acid) hydrogel [65]. Thus it corroborates this results.

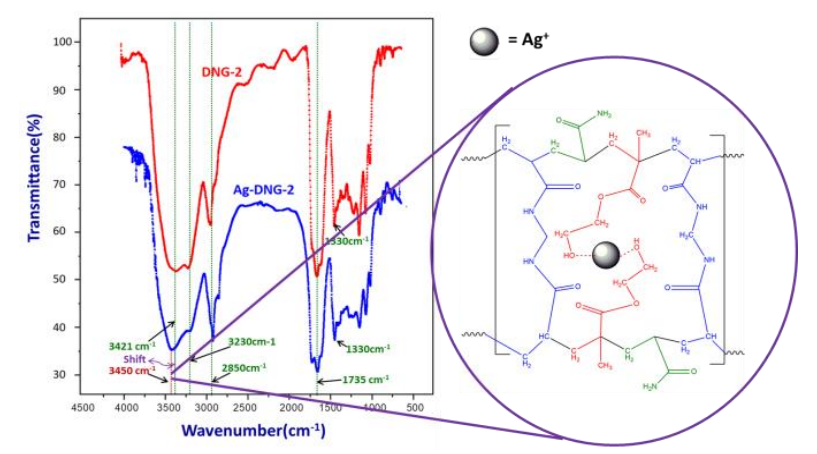

Fig. 2. FTIR Spectra of Virgin DN and Silver Nanoparticles Embedded DN Nanocomposite Hydrogel.

\section{XRD analysis}

The X-ray diffractograms of the virgin and silver nanoparticles embedded DN hydrogels, recorded from $20^{\circ}$ to $80^{\circ}$, are provided in Fig. 3. The amorphous nature of the double network hydrogels (DNG-1, DNG-2 and DNG-3) is confirmed by the absence of Bragg diffraction peaks in their diffractograms indicating a lack of long-range periodicity in the hydrogels. However, five diffraction peaks at $2 \theta$ values of $38.37^{\circ}, 46.30^{\circ}, 55.02^{\circ}, 64.64^{\circ}$ and $77.72^{\circ}$ for AgNPs embedded DN nanocomposite hydrogel samples are observed. Such diffractions corresponding to (111), (200), (142), (220) and 
(311) planes, respectively which can be indexed according to the facets of face centered cubic crystal structure of silver particles [66]. The inter-planar spacing ('d') values are calculated to be $2.336,1.955,1.436$ and $1.224 \AA$ for (111), (200), (220) and (311) planes, respectively which match with the standard silver values. The comparison of the given XRD spectra with the standard (JCPDS file No.040783) confirms the successful formation of crystalline silver nanoparticles inside the DN hydrogels [67].
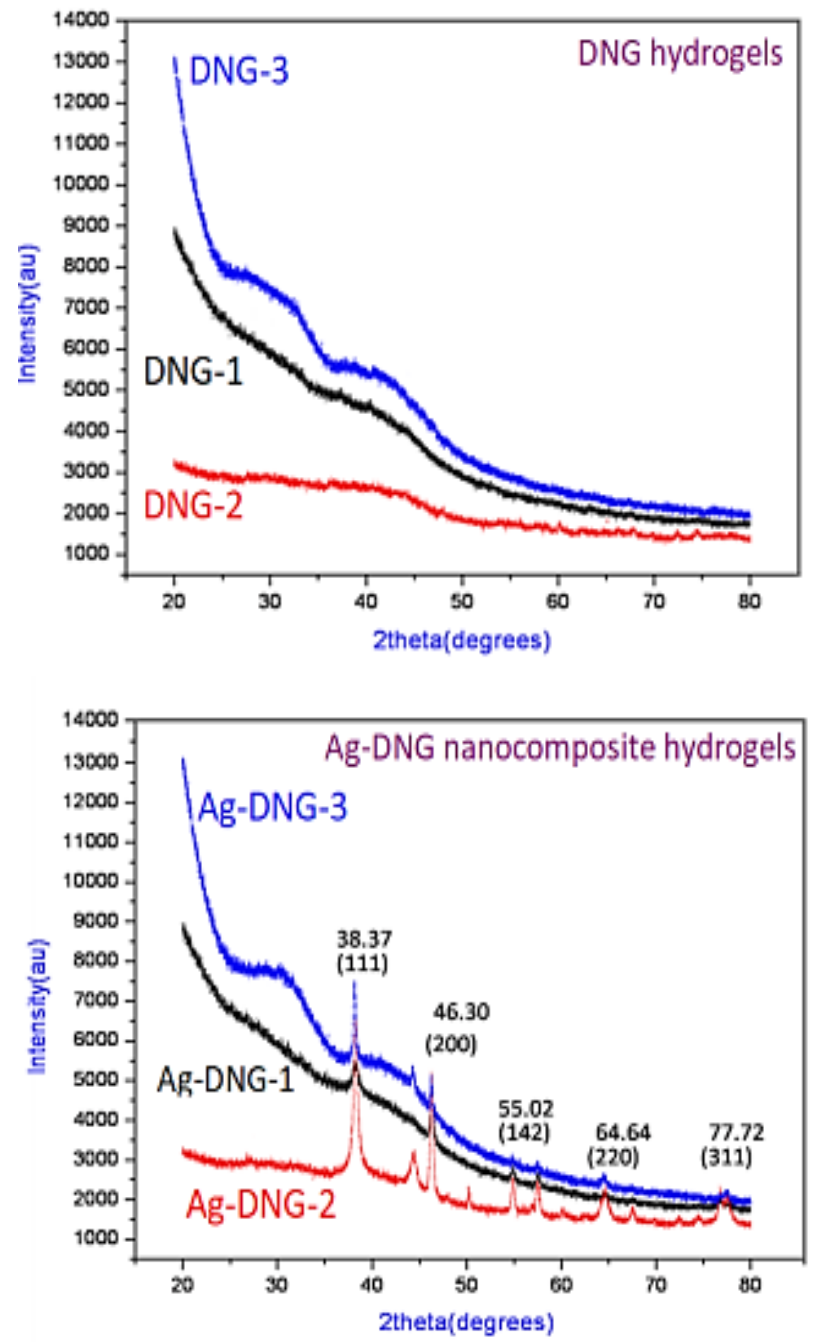

Fig. 3. XRD Diffractograms of Virgin and Silver Nanoparticles Embedded Hydrogels.

\section{TEM analysis}

Silver nanoparticles embedded double network hydrogels of PVA-Borax $\left(1^{\text {st }}\right.$ network) and crosslinked P(AM-co-HEMA) (2 ${ }^{\text {nd }}$ network) were analyzed by TEM measurement. Fig. 4 illustrates the TEM micrographs for a typical sample (Ag-DNG-2). The diameter and the distribution size of the silver nanoparticles present in the DN nanocomposite hydrogels were evaluated. The average size of silver nanoparticles was observed to be $20-50 \mathrm{~nm}$.
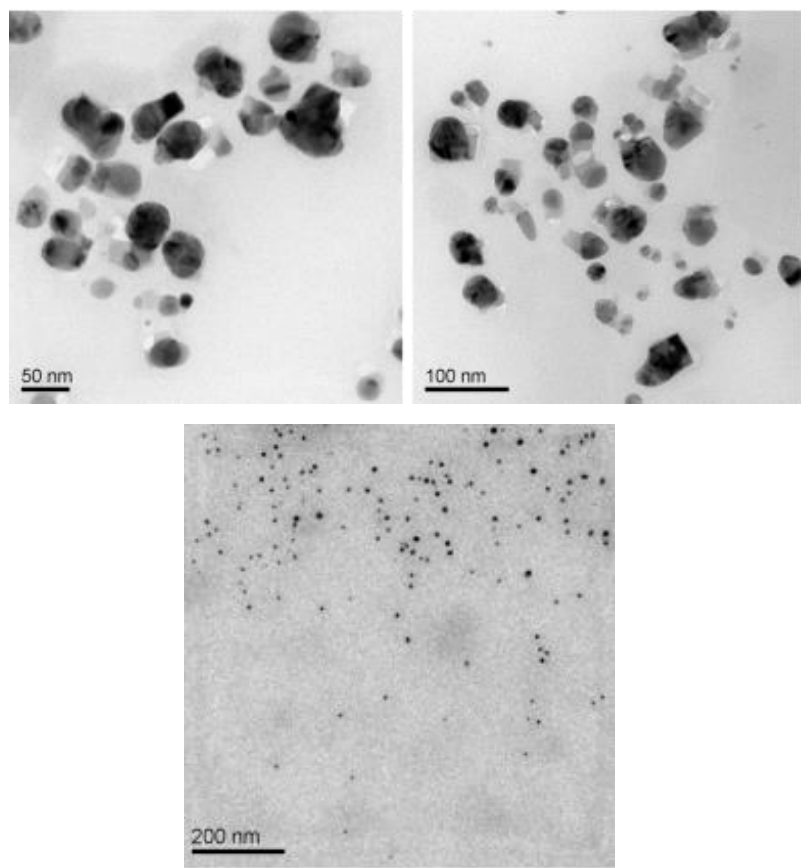

Fig. 4. TEM Images of a Silver Nanoparticles Embedded DN Nanocomposite Hydrogel (Ag-DNG-2).

\section{Swelling characteristics of Ag-DNG hydrogels}

Swelling tests were performed with a view to evaluate the swelling capacity of the hydrogel samples in distilled water. The degree of swelling of hydrogels was directly related to the duration of swelling process. This swelling behavior could be related to the water absorption mechanism which is determined by diffusion process of water molecules into hydrogels. Swelling curves of controlled DNG samples and also of AgNPs embedded nanocomposite hydrogels (Ag-DNG) are shown in Fig. 5. The equilibrium swelling and time needed to achieve this equilibrium were measured from the swelling curves (Table 2). Time for achieving equilibrium swelling is lowest for the double network hydrogel with $100 \mathrm{wt} \%$ acrylamide content in the second network of the DN hydrogel than that of the DN hydrogels without AM (only HEMA) or AM/HEMA containing DN hydrogels in the second network ( $1^{\text {st }}$ network was constant for all the sample). This may be due to the more hydrophilic nature of acrylamide compared to HEMA unit. Further, addition of $\mathrm{Ag}$ nanoparticles in the DN hydrogels also reduced the degree of swelling and enhanced the time to achieve equilibrium swelling of the hydrogels which might be because of reduction of vacant spaces inside hydrogels due to occupation of the Ag-nanoparticles in them.

The equilibrium degree of swelling was observed to follow the sequence: DNG-1 > DNG-2 > DNG-3 which is because of the presence of more concentration of hydrophilic AM unit in DNG-1 hydrogel $(100 \%$ $\mathrm{AM})$ than that of the other two samples: DNG-2 (having 50/50 wt\% AM/HEMA) and DNG-3 (having 100\% HEMA). Also the equilibrium degree of swelling for the AgNPs embedded nanocomposite hydrogels (Ag-DNG) was less than that of 
corresponding virgin hydrogels (DNG) which is because of the presence of Ag-nanoparticles at the available vacant space in the hydrogels which hindered the entrapment of water molecules in the hydrogels. Similar results of lowering of swelling rate in $\mathrm{Ag}$ particles incorporated nanocomposite hydrogel than that of the corresponding virgin hydrogel was also observed by Mohan et al. [68].

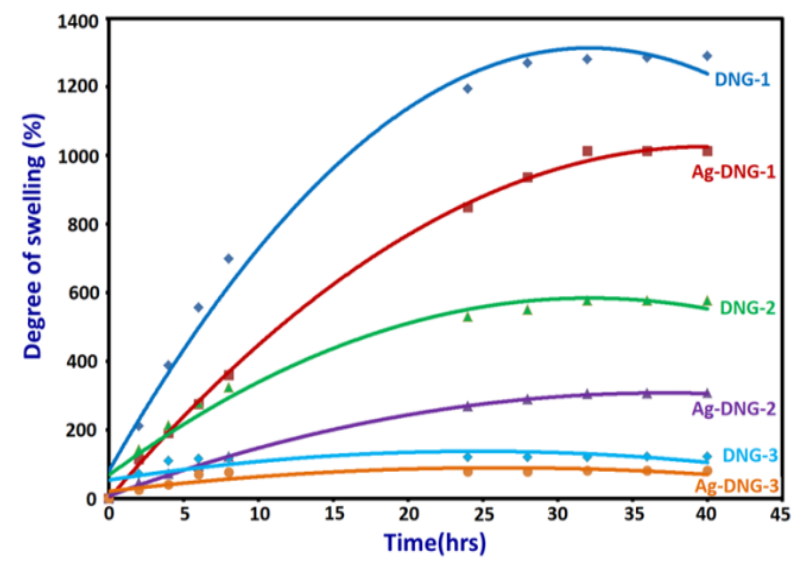

Fig. 5. Swelling of Ag-NPs Embedded DN Nanocomposite Hydrogels.

Table 2. Synthesis of AgNPs embedded DN nanocomposite hydrogels and their degree of equilibrium swelling.

\begin{tabular}{c|c|c|c|c}
\hline $\begin{array}{c}\text { Sl. } \\
\text { No. }\end{array}$ & $\begin{array}{c}\text { Sample } \\
\text { Code }\end{array}$ & $\begin{array}{c}\text { Amount } \\
\text { of } \\
\text { Embedded } \\
\text { AgNPs } \\
\text { (wt\%) }\end{array}$ & $\begin{array}{c}\text { Equilibrium } \\
\text { Degree } \\
\text { Swelling } \\
(\%)\end{array}$ & $\begin{array}{c}\text { Time of } \\
\text { Equilibrium } \\
\text { Swelling } \\
\text { (hrs) }\end{array}$ \\
\hline 1. & $D N G-1$ & 0 & 1315 & 27 \\
\hline 2. & $A g-D N G-1$ & 6.91 & 1012 & 32 \\
\hline 3. & $D N G-2$ & 0 & 576 & 30 \\
\hline 4. & $A g-D N G-2$ & 4.86 & 305 & 34 \\
\hline 5. & $D N G-3$ & 0 & 120 & 34 \\
\hline 6. & $A g-D N G-3$ & 2.67 & 80 & 36 \\
\hline
\end{tabular}

\section{Kinetics of swelling}

The kinetic study for the AgNPs embedded DN hydrogels were examined by plotting $t / S$ versus $t$. Fig. 6 is showing linear regression of the swelling curves for the hydrogel samples (Eq. 3). The various parameters like initial swelling rate, the swelling rate constant $\left(\mathrm{K}_{\mathrm{s}}\right)$ and the values of theoretical equilibrium swelling $\left(\mathrm{S}_{\mathrm{eq}}\right)_{\max }$ for all the synthesized hydrogel samples were calculated from the slope and the intersection of the lines. The results are provided in Table 3.

Table 3. Swelling parameters of AgNPs embedded DN nanocomposite hydrogels.

\begin{tabular}{c|l|c|c|c|c|c}
\hline $\begin{array}{c}\text { Swelling } \\
\text { Parameters }\end{array}$ & \multicolumn{7}{|c}{ Hydrogel Samples } \\
\cline { 2 - 7 } & $\begin{array}{c}\text { DNG } \\
\mathbf{1}\end{array}$ & $\begin{array}{c}\text { Ag- } \\
\text { DNG } \\
\mathbf{1}\end{array}$ & $\begin{array}{c}\text { DNG } \\
\mathbf{2}\end{array}$ & $\begin{array}{c}\text { Ag- } \\
\text { DNG } \\
\mathbf{2}\end{array}$ & $\begin{array}{c}\text { DNG } \\
\mathbf{3}\end{array}$ & $\begin{array}{c}\text { Ag- } \\
\text { DNG } \\
\mathbf{3}\end{array}$ \\
\hline $\mathrm{A}$ & 0.0087 & 0.0179 & 0.0112 & 0.0319 & 0.0231 & 0.0786 \\
\hline $\mathrm{B}$ & 0.0004 & 0.0004 & 0.0014 & 0.0016 & 0.0021 & 0.0029 \\
\hline $\mathrm{S}_{\mathrm{eq}}(\%)$ & 2500 & 2500 & 714 & 625 & 476 & 344 \\
\hline $\mathrm{K}_{\mathrm{s}}\left(\mathrm{hr}^{-1}\right)$ & 1840 & 9000 & 17000 & 8020 & 1910 & 1070 \\
\hline
\end{tabular}

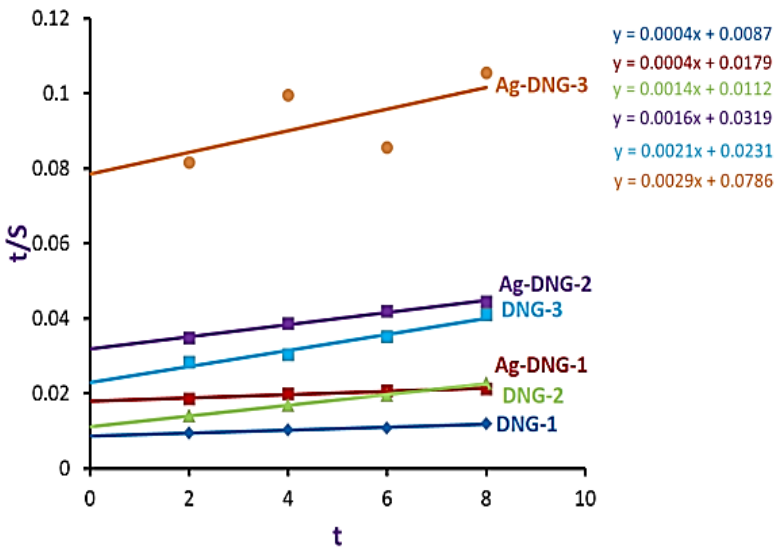

Fig. 6. Swelling kinetic plot of $(t / S)$ versus time (t) of the hydrogels.

When hydrogel samples were immersed in distilled water, the water molecules diffused into the samples which resulted in the swelling of the hydrogels. Diffusion occurred due to the migration of water molecules into the pre-existing and dynamically formed spaces inside the hydrogel samples. The swelling process of the hydrogels is associated with a larger scale segmental motion which results in increase in the distance of separation between network chains.

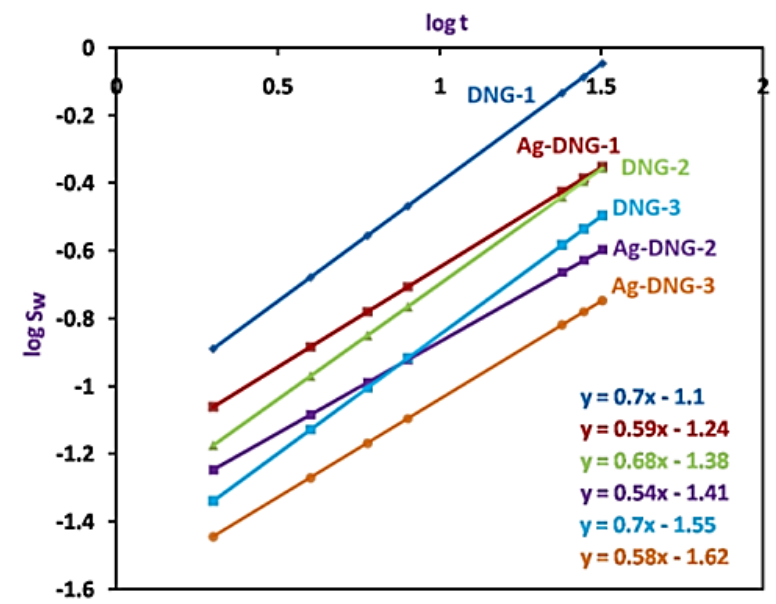

Fig. 7. Swelling kinetic plot $\left(\log \mathrm{S}_{\mathrm{w}}\right.$ versus $\left.\log \mathrm{t}\right)$ of the hydrogels.

The swelling kinetics of hydrogels were further determined (using Eq. 5) by plotting $\log S_{w}$ versus $\log t$ (Fig. 7). The swelling characteristic constants (K) and the values of transport exponent (n) are provided in Table 4. The transport exponent i.e., ' $n$ ' determines the mode of transportation (diffusion) of water molecules into the hydrogel samples. If the value of $n=0.45-0.50$, it corresponds to Fickian diffusion, whereas $0.50<\mathrm{n}$ $<1.0$ indicates non-Fickian anomalous diffusion. Fickian diffusion has the slower rate of solvent diffusion as compared to the rate of relaxation of polymeric chains; while, in non-Fickian anomalous swelling, diffusion rate is comparable to the rate of relaxation of polymer chains. On the other hand, when $\mathrm{n}=1.0$, it is said to be ideal non-Fickian swelling in which rate of diffusion of the solvent is more than the rate of chain relaxation. The values of ' $n$ ' for all the 
hydrogel samples (like DNG-1, Ag-DNG-1, DNG-2, Ag-DNG-2, DNG-3 and Ag-DNG-3) lie in between 0.5 and 1.0 which indicate that the swelling of all the hydrogels (both virgin and AgNPs embedded nanocomposite hydrogels) is non-Fickian anomalous in nature. However, the swelling rate constants of all the AgNPs incorporated nanocomposite hydrogels are lower than that of the corresponding virgin hydrogels. This is because of the presence of Ag nanoparticles which occupied the void space of the hydrogels resulting such characteristics

Table 4. Swelling characteristic constants for AgNPs embedded DN nanocomposite hydrogels.

\begin{tabular}{c|c|c|c}
\hline SI.No. & Sample Code & $\mathbf{n}$ & K \\
\hline 1. & DNG-1 & 0.70 & 0.079 \\
\hline 2. & Ag-DNG-1 & 0.59 & 0.058 \\
\hline 3. & DNG-2 & 0.68 & 0.042 \\
\hline 4. & Ag-DNG-2 & 0.54 & 0.038 \\
\hline 5. & DNG-3 & 0.70 & 0.028 \\
\hline 6. & Ag-DNG-3 & 0.58 & 0.023 \\
\hline
\end{tabular}

\section{Antimicrobial study}

Silver nanoparticles are active materials having antimicrobial activity which when embedded into hydrogels, the synthesized silver nanocomposite hydrogel as a whole exhibited antibacterial activity because of the decent dispersion of silver nanoparticles throughout the network of the hydrogels [69]. The antimicrobial activity is basically a release of silver nanoparticles from the Ag-DNG nanocomposite hydrogels. Ag-nanoparticles exhibit powerful antibacterial activity by binding it with the DNA of the microbes, thereby avoiding the bacterial replication [70]. DNG hydrogels when kept in an open atmosphere for 10 days, they were infected by the microbes (Fig. 8). However, when these hydrogels were embedded with silver nanoparticles, the microbial infection was not observed. The antimicrobial tests of the hydrogels were further carried out against Escherichia coli (Gram -ve bacteria) and Bacillus subtilis (Gram +ve bacteria). The results of antibacterial activity study are shown in Fig. 9. It can be seen that all the Ag-DNG hydrogels have antibacterial activity. The inhibition area of the Ag-DNG hydrogels follows the order: Ag-DNG-1>Ag-DNG-2>Ag-DNG-3 (Table 5). This behavior is due to the abundance of small size Ag nanoparticles spread over the prepared Ag-DNG nanocomposite hydrogels. A recent study showed that the antibacterial effect of $\mathrm{Ag}$ nanoparticles mostly depends on the particle size where Ag nanoparticles with smaller sizes are more efficient and deduced that 1-10 $\mathrm{nm}$ have a direct interaction with the microbes [71]. Silver nanoparticles (AgNPs) embedded composite hydrogels like P(AA-co-PEGMA), chitosan wafer-loaded PVA hydrogels, PVA/PVP-based hydrogels, pH-sensitive poly(methyl methacrylate-comethacrylic acid) hydrogels were also reported to have similar potential antibacterial activity [72-76].

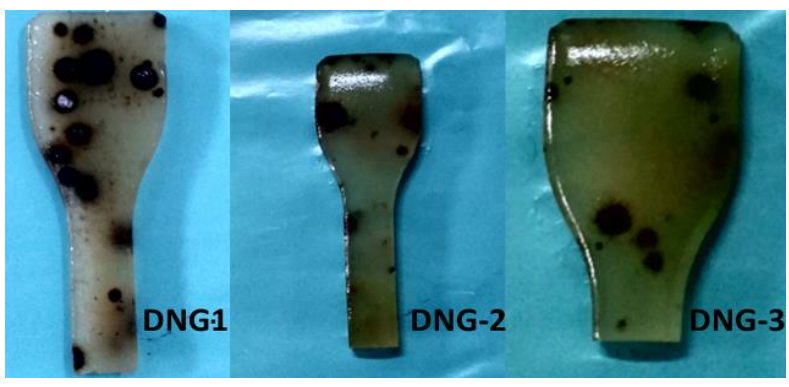

Fig. 8. Microbial infection in DNG hydrogels when they were kept in open air for 10 days.

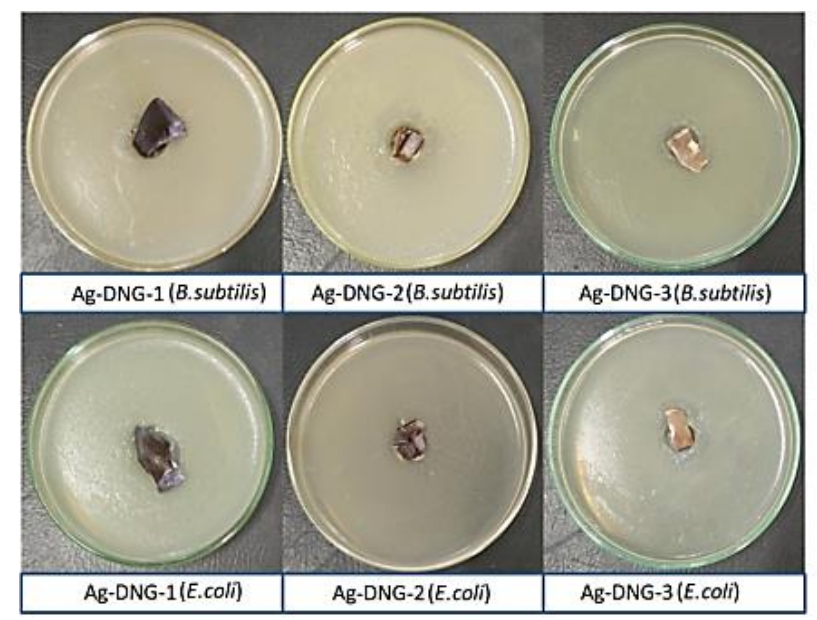

Fig. 9. Photographs showing the effect of Ag-nanoparticles embedded hydrogels upon bacterial activity.

Table 5. The inhibition zone diameter values (in $\mathrm{mm}$ ) of Ag-DNG nanocomposite hydrogels tested against Gram +ve (E. coli) and Gram -ve (B. subtilis) bacteria.

\begin{tabular}{c|c|c}
\hline Sample code & $\begin{array}{c}\text { Gram positive } \\
\text { (B. subtilis) }\end{array}$ & $\begin{array}{c}\text { Gram negative } \\
\text { (E. coli) }\end{array}$ \\
\hline Ag-DNG-1 & 8.9 & 8.2 \\
\hline Ag-DNG-2 & 7.5 & 7.9 \\
\hline Ag-DNG-3 & 5.4 & 5.8 \\
\hline
\end{tabular}

\section{Conclusion}

Silver nanoparticles (AgNPs) were successfully embedded into high strength double network hydrogels [of PVA-borax as the first network and crosslinked $\mathrm{P}(\mathrm{AM}$-co-HEMA) as the second network] by in-situ reduction of silver(I) ions. The degree of equilibrium swelling of virgin hydrogels having more AM content is more than that of the DN hydrogels having less AM content or no AM content (only HEMA). Thus, degree of equilibrium swelling decreases from DNG-1 to DNG-2 to DNG-3 hydrogels because of the different nature of AM and HEMA monomer (AM unit is more hydrophilic in nature than that of HEMA unit) and their composition (AM and HEMA) in different hydrogels. The swelling capacities of the resulting Ag-DNG nanocomposite hydrogels were further evaluated which showed the following trends: Ag-DNG-1>Ag-DNG2>Ag-DNG-3. The highest swelling capacity of $\mathrm{Ag}$ DNG-1 may be because of the presence of more hydrophilic AM moieties as compared to the Ag DNG- 
2 and in Ag-DNG-3 hydrogels. Furthermore, Ag-DNG nanocomposite hydrogels exhibited inferior swelling tendency as compared to virgin DNG hydrogels because of reduction of the availability of vacant space in DNG hydrogel as AgNPs occupied some of the empty voids of the DN hydrogels. The swelling kinetic study revealed that the diffusion of solvent molecules inside both virgin and AgNPs embedded DN hydrogels followed the non-Fickian type behavior.

FTIR spectroscopic investigations elucidated that the $\mathrm{Ag}^{+}$ions are entrapped inside the hydrogel networks via ion-diploe interaction forming metal-ligand type of complex using the hydroxyl $(\mathrm{OH})$ group. XRD analysis demonstrated the appearance of characteristic peaks of face centered cubic crystal structure of silver nanoparticles in the DNG hydrogels. The Ag-DNG nanocomposite hydrogels were characterized for size distribution of Ag nanoparticles using TEM analysis which concluded that the average size of silver nanoparticles was 20-50nm.

Antimicrobial activity of the AgNPs embedded DN nanocomposite hydrogels was investigated. It indicated that Ag-NPs embedded DN hydrogels exhibited antimicrobial activity whereas the virgin hydrogels did not showed any such property. Also antimicrobial activity was exhibited highest for Ag-DNG-1due to the highest abundance of silver nanoparticles in such hydrogels than that of the other nanocomposite hydrogels (Ag-DNG-2 and Ag-DNG-3). Such AgNPs embedded DN nanocomposite hydrogels having antibacterial property (both for Escherichia coli and Bacillus subtilis) may find potential biomedical application

\section{Acknowledgements}

The authors are thankful to Prof. P. K. Dutta, MNNIT Allahabad and ACMS, IIT Kanpur for providing characterization facilities of Antimicrobial activity and TEM analysis, respectively.

\section{References}

1. Bag, D.S.; Saxena, A.K.; "Smart Gels" in "Kirk-Othmer Encyclopedia of Chemical Technology", John Wiley and Sons, Newyork, USA, 2014, 1.

2. Bag, D.S.; Rao K.U.B.; J. Polym. Mater., 2006, 23, 225.

3. Kelmanovich, S.G.; Parke-Houben, R.; Frank, C.W.; Soft Matter., 2012, 8, 8137

4. Doring, A.; Birnbaun, W.; Kuckling, D.; Chem. Soc. Rev., 2013, 42,7391 .

5. Lin-Gibson, S.; Bencherif, S.; Cooper, J. S.; Wetzel, S. F.; Antonucci, J. M.; Vogel, B. M.; Horkay, F.; Washburn, N. R.; Biomacromolecules, 2004, 5, 1280.

6. Netti, P. A.; Shelton, J. C.; Revell, P. A.; Piric, C.; Smith, S.; Ambrosio, L.; Nicolais, L.; Bonfield, W.; Biomater., 1993, 14, 1098.

7. Sander, C.G.; Leeuwenburgh, C.; Jo, J.; Wang, H.; Yamamoto, M.; Jansen, J.A.; Yasuhiko, T.; Biomacromolecules, 2010, 11, 154.

8. Sophier, J.; Corre, P.; Weiss, P.; Layrolle, P.; Acta Biomater., 2010, 6, 2932.

9. Silverman, L.; Boskey, A.L.; Calcif. Tissue Int., 2004, 75, 494.

10. Lowenstam, H.A.; Weiner, S.; On Biomineralization, Oxford University Press; New York: 1989.

11. Karpati-Smidroczki, E.; Buki, A.; Zrinyl, M.; Colloid Polym. Sci., 1995, 273, 857.
12. Yokoi, T.; Kawashita, M.; Kikuta, K.; Ohtsuki, C.; Mater. Sci. Eng. C., 2010, 30, 154

13. Li, H.; Xin, H.L.; Muller, D.A.; Estroff, L.A.; Sci., 2009, 32, 1244.

14. Huang, J.; Liu, G.; Son, C.; Saiz, E.; Tomsia, A.P.; Chem. Mater., 2012, 24, 1331.

15. Gong, J. P.; Soft Matter, 2010, 6, 2583.

16. Na, Y.; Kurokawa, T.; Katsuyama, Y.; Tsukeshiba, H.; Gong, J. P.; Osada, Y.; Okabe, S.; Karina, T.; Shibayama, N.; Macromol., 2004, 37, 5370

17. Webber, R. E.; Creton, C.; Brown, H. R.; Gong, J. P.; Macromolecules., 2007, 40, 2919

18. Haque, M. A.; Kurokawa, T.; Gong, J. P.; Polymer, 2012, 53, 1805.

19. Zhang, J. L.; Huang, W. M.; Gao, G.; Fu, J.; Zhou, Y.; Salvekar, A. V.; Venkatraman, S. S.; Wong, Y. S.; Tay, K. H.; Birch, W. R.; Eur. Polym. J., 2014, 58, 41.

20. Okumura, Y.; Ito, K.; Adv. Mater., 2001, 13, 485

21. Hu, Z.; Chen, G.; Adv. Mater., 2014, 26, 5950.

22. Sasaki, M.; Karikkineth, B. C.; Nagamine, K.; Kaji, H.; Torimitsu, K.; Nishizawa, M.; Adv. Healthcare Mater., 2014, 3, 1919.

23. Lin, S.; Cao, C.; Wang, Q.; Gonzalez, M.; Zhao, X.; Soft Matter, 2014, 10, 7519.

24. Haraguchi, K.; Takehisa, T.; Adv. Mater., 2002, 14, 1120.

25. Satarkar, N. S.; Biswala, D.; Hilt, J. Z.; Soft Matter, 2010, 6 , 2364.

26. Schlichting, K.E.; Johnson, T.M.C.; Goodman, M.; Lipert, R.J.; Prozorov, T.; Liu, X.; McKinley, T.O.; Lin, Z.; Martin, J.A.; Acta Biomaterialia, 2011, 7, 3094.

27. Gaharwar, A.K.; Rivera, C.P.; Kiuand, C.J.; Schmidt, G.; Acta Biomaterialia, 2011, 7, 4139.

28. Fan, J.; Shi, Z.; Lian, M.; Li, H.; Yin, J.; J. Mater. Chem., 2013, 1,7433 .

29. Du, J.; Xu, S.; Feng, S.; Yu, L.; Soft Matter., 2016, 12, 164.

30. Gong, J.P.; Katsuyama, Y.; Adv. Mater., 2003, 15, 1155

31. Vlierberghe, S.V.; Dubruel, P.; Schach, E.; Biomacromolecules, 2011, 12, 1387.

32. Hervás-Pérez, J.P.; López-Cabarcos, E.; López-Ruiz, B.; Biomol. Eng., 2006, 23, 233.

33. Dutta, S.; Dey, D.; Dhara, D.; J. Appl. Polym. Sci., 2014, 131, 39873.

34. Selby, A.; Maldonado-Codina, C.; Derby, B.; J. Mech. Behav. Biomed. Mater., 2014, 35, 144

35. Martin, B. D.; Linhardt, R. L.; Dordick, J. S.; Biomaterials, 1998, 19,69

36. Roberts, J. J.; Bryant, S. J.; Biomaterials, 2013, 34, 9969

37. Wang, J. J.; Liu, F.; J. Appl. Polym. Sci., 2012, 125, 548

38. Kaner, D.; Friedmann, A. J.; Clin. Periodontol, 2010, 38, 95

39. Zhou, C.; Li, P.; Qi, X.; Sharif, A.; Poon, Y. F.; Cao, Y.; Chang, M. W.; Leon, S. S.; Chan-Park, M. B.; Biomaterials, 2011, 270, 2704

40. Killion, J. A.; Geever, L. M.; Devine, D. M.; Farrell, H.; Higginbotham, C. L.; Int. J. Polym. Mater., 2014, 63, 650

41. Montanaro, L.; Speziale, P.; Campoccia, D.; Ravaioli, S.; Cangini, I.; Pietrocola, G.; Giannini, S.; Arciola, C.R.; Future Microbiol., 2011, 6, 1329

42. Morris, K.; Lancet Infect. Dis., 2007, 7, 509

43. Guzmán, M.; Dille, J.; Stephane, G.; Nanomedicine, 2012, 8, 37

44. Kalishwaralal, K.; BarathManiKanth, S.; Sureshbabu, R.K.P.; Venkataraman, D.; Sangiliyandi, G.; Colloids Surf. B: Biointerfaces, 2010, 72, 340

45. Nadworny, P. L.; Wang, J.; Tredget, E. E.; Burrel, R. E.; Nanomedicine, 2008, 4, 241.

46. Gurunathan, S.; Lee, K. J.; Kalishwaralal, K.; Sheikpranbabu, S.; Vaidyanathan, R.; Eom, S. H.; Biomaterials, 2009, 30, 6341.

47. Jain, P.; Pradeep, T.; Biotechnol. Bioeng., 2005, 90, 59.

48. Bosetti, M.; Masse, A.; Tobin, E.; Cannas, M.; Biomaterials, 2002, 23, 887 .

49. Hillyer, J. F.; Alrecht, R. M.; J. Pharm. Soc., 2001, 90, 1927.

50. Zuhuang, J.; Patent number CN 1387700, 2003.

51. Chen, M.; Chen, S.; Patent number CN 1355335, 2002

52. Perni, S.; Hakala, V.; Prokopovich, P.; Colloids Surf. A., 2014, 406, 219. 
53. Sharma, V. K.; Siskova, K. M.; Zboril, R.; Gardea-Torresdey, J. L.; Adv. Colloid Interf. Sci., 2014, 204, 15.

54. Katiyar, R.; Bag, D.S.; Nigam, I., Adv. Mat. Lett., 2014, 5, 214.

55. Katiyar, R.; Bag, D.S.; Nigam, I., J. Polym. Mater., 2013, 30, 15.

56. Dixit, A.; Bag, D. S.; Kalra, S. J. S.; Polymer, 2017, 119, 263.

57. Liu, J.; Zheng, X. L.; Tang, K. Y.; Rev. Adv. Mater. Sci., 2013, 33,45

58. Saraydin, D.; Karadag, E.; Guven, O.; Polym. Bull., 1998, 4, 577.

59. Peniche, C.; Cohen, M. E.; Vazquez, B.; Roman, J. S.; Polymer, 1997, 5977

60. Saraydinetal, D.; Appl Biotechnol, 1992, 82, 115

61. Druzynska, M. G.; Czubenko, J. O.; Prog. Chem. Appl., 2012 17,59

62. Cruickshank, R.; Duguid, J. P.; Marion, B. P.; Swain, R.H.A.; Medicinal Microbiology, 12th Ed., Vol. II, Churchill Livingstone, London, 1975, 196.

63. Koysuren, O.; Karaman, M.; Dinc, H.; J. Appl. Polym. Sci., 2012, 124, 2736.

64. Spoljaric, S.; Salminen, A.; Luong, N. D.; Seppala, J.; Eur. Polym. J., 2014, 56, 105.

65. Bag, D. S.; Alam. S.; Mathur, G. N.; Smart Mater. Struct., 2004 $13,1258$.

66. Prakash, P.; Gnanaprakasam, P.; Emmanuel, R.; Arokiyaraj, S.; Saravanan, M.; Colloids Surf B Biointerfaces, 2013, 108, 255.

67. limuthu, K.; Babu, R.S.; Venkataraman, D.; Bilal, M.; Gurunathan, S.; Colloids Surf B Biointerfaces, 2008, 65, 150

68. Mohan, Y. M.; Lee, K.; Premkumar, T.; Geckeler, K. E.; Polym., 2007, 48, 158

69. Li, S.; Dong, S.; Xu, W.; Tu, S.; Yan, L.; Zhao, C.; Ding, J.; Chen, X.; Adv. Sci. 2018, 1700527, 1.

70. Aggor, F. S.; Ahmed, E. M.; El-Aref A. T.; Asem, M. A.; J. Am. Sci., 2010, 6, 12

71. Morones, J. R.; Elechiguerra, J. L.; Camacho A, Holt, A.; Kouri, J. B.; Ramírez, J. P.; Yacaman, M. J.; Nanotechnology, 2005, 16, 2346

72. Lee, W. F.; Tsao, K. T.; J. Mater. Sci. 2009, 45, 89.

73. Jaiswal, M.; Koul, V.; Dinda, A. K.; J. Appl. Polym. Sci. 2016, $133,43472$.

74. Wu, J.; Hou, S.; Ren, D.; Mather, P. T.; Biomacromolecules, 2009, 10, 2686.

75. Eid, M.; El-Arnaouty, M. B.; Salah, M.; Soliman, E. S.; Hegazy, E. S. A.; J. Polym. Res. 2012, 19, 9835.

76. Wei, Q. B.; Fu, F.; Zhang, Y. Q.; Tang, L.; J. Polym. Res. 2014, 21,349 . 